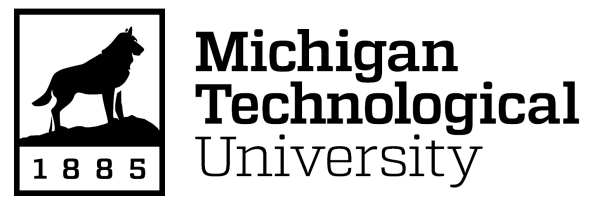

Michigan Technological University Digital Commons @ Michigan Tech

$11-1-2001$

\title{
Comments on "Errors in the estimate of the fractal correlation dimension of raindrop spatial distribution"
}

\author{
A. R. Jameson \\ RJH Scientific, Inc. \\ Alexander Kostinski \\ Michigan Technological University
}

Follow this and additional works at: https://digitalcommons.mtu.edu/physics-fp

Part of the Physics Commons

\section{Recommended Citation \\ http://dx.doi.org/10.1175/1520-0450(2001)040<2098:COEITE>2.0.C0;2 \\ Retrieved from: https://digitalcommons.mtu.edu/physics-fp/246 \\ Follow this and additional works at: https://digitalcommons.mtu.edu/physics-fp \\ Part of the Physics Commons}

Jameson, A. R., \& Kostinski, A. (2001). Comments on "Errors in the estimate of the fractal correlation dimension of raindrop spatial distribution". Journal of Applied Meteorology, 40(11), 2098-2098. 


\title{
NOTES AND CORRESPONDENCE
}

\section{Comments on "Errors in the Estimate of the Fractal Correlation Dimension of Raindrop Spatial Distribution"}

\author{
A. R. JAMESON \\ RJH Scientific, Inc., Alexandria, Virginia \\ A. B. KostinsKI \\ Department of Physics, Michigan Technological University, Houghton, Michigan
}

10 April 2001

We are pleased to see that this work by Gabella et al. (2001) confirms our earlier findings (Jameson and Kostinski 1998, appendix), of which unfortunately Gabella et al. apparently were unaware when writing their note. This situation is somewhat embarrassing given that both papers appear in journals of the American Meteorological Society (AMS), and it suggests that searches should be conducted routinely through the AMS journal archive database by authors, editorial staff, and reviewers, not only to help to establish originality but also for identifying appropriate reviewers.

In particular, we note that the authors' use of Monte Carlo simulations is identical to that in Jameson and Kostinski (1998), because the application of the uniform distribution for determining the $x$ and $y$ coordinates of each drop is equivalent to the binomial distribution (or to the Poisson distribution in the limit of low probability of the occurrence of a drop) that was used in Jameson and Kostinski (1998) for determining the location of 453 drops. Moreover, like Jameson and Kostinski (1998), the authors numerically simulate the LovejoySchertzer (1990) observations of 452 drops over a 1.28 $\mathrm{m} \times 1.28 \mathrm{~m}$ area to conclude that the so-called fractal dimension of less than two, deduced by Lovejoy and Schertzer, is in fact an artifact of undersampling (Jameson and Kostinski 1998, p. 294). We admit that the authors do a more complete analysis than we thought was necessary (Jameson and Kostinski 1998), because this point was relatively minor as compared with our larger concerns. However, in essence, Gabella et al.

Corresponding author address: A. R. Jameson, 5625 N. 32d St., Arlington, VA 22207-1560.

E-mail: jameson@rjhsci.com
(2001) adds less to our understanding than it at first appears to do.

We also wish to clarify a misunderstanding in the abstract of Gabella et al. (2001). To be specific, the opposite of statistically homogeneous rain is not fractal rain but rather is statistically inhomogeneous rain [see discussion in Jameson and Kostinski $(2001 \mathrm{a}, \mathrm{b})]$. We doubt the actual existence of fractal rain (Jameson and Kostinski 2000, 382-383), but if it were to exist, it would be statistically homogeneous as well, at least for a fixed resolution. Of interest, however, from the perspective of a radar having a sampling volume that increases with greater distance from the radar, fractal rain would appear to be statistically inhomogeneous because the mean drop concentration would actually decrease with increasing distance, as pointed out by Lovejoy and Schertzer (1990).

\section{REFERENCES}

Gabella, M., S. Pavone, and G. Perona, 2001: Errors in the estimate of the fractal correlation dimension of raindrop spatial distribution. J. Appl. Meteor., 40, 664-668.

Jameson, A. R., and A. B. Kostinski, 1998: Fluctuation properties of precipitation. Part II: Reconsideration of the meaning and measurement of raindrop size distributions. J. Atmos. Sci., 55, 283294.

— and 2000: Fluctuation properties of precipitation. Part VI: Observations of hyperfine clustering and drop size distribution structures in three-dimensional rain. J. Atmos. Sci., 57, 373-388.

__ and _ 2001a: Reconsideration of the physical and empirical origins of $Z-R$ relations in radar meteorology. Quart. J. Roy. Meteor. Soc., 127, 517-538.

— and - 2001b: What is a raindrop size distribution? Bull. Amer. Meteor. Soc., 82, 1169-1177.

Lovejoy, S., and D. Schertzer, 1990: Fractals, raindrops and resolution dependence of rain measurements. J. Appl. Meteor., 29, 11671170 . 